\title{
Studying temperature component variations in relation with the increase of the atmosphere carbon dioxide in Fars province, Iran
}

\author{
Azadeh Arbabi Sabzevari ${ }^{1}$ and Gholam Reza Miri ${ }^{*}$ \\ ${ }_{1}^{1}$ Islamic Azad University, Islamshahr Branch, Department of Geography, Tehran, Iran. \\ $2^{2}$ Islamic Azad University, Zahedan Branch, Department of Geography, Zahedan, Iran. \\ gholam_reza_miri@yahoo.com*
}

\begin{abstract}
This study has attempted to survey the relationship between temperature variations in Fars province and the variation in the rate of carbon dioxide emitted into the atmosphere. For this purpose, the temperature data (mean, minimum and maximum) of Shiraz, Abadeh, Lar, Doroodzan dam, Zarghan and Fasa stations, were extracted from Iran Meteorology Organization in a 15-year statistical period (1990-2005). First, the going trend in the temperature data of the above stations was studied. Then the relation between the rate of atmosphere carbon dioxide as registered in Manaloa station with the temperature parameters of these stations have been evaluated by using two-variable correlation and linear regression in both monthly and annual scale. The obtained results indicate that three parameters of mean, minimum and maximum temperature have the rising trend in all stations, among which the minimum temperature has allocated the highest rate of increase to itself. Furthermore, the results indicate that the highest correlation between the atmosphere carbon dioxide and temperature parameters is related to the months of February, March and October that the minimum temperature has allocated the highest correlation coefficient in both monthly and annual scale. Also, among the studied stations, the minimum temperature of Fasa station has the most significant coefficient with the rate of atmosphere carbon dioxide.
\end{abstract}

Keywords: Temperature, Carbon Dioxide, Climate Change, Fars province

\section{Introduction}

In the past 200 years and especially in the recent 50 years, the greenhouse gasses emission have risen sharply. For example, now the carbon dioxide and methane gases in atmosphere have increased by 30 and $150 \%$ compared to that of pre- industrial revolution; and carbon dioxide resulting from fossil fuels is considered as the major human-made greenhouse gas (Vaseghi et al., 2009). It is generally believed that such increase in greenhouse gases is related to the regional and world climate change (Chang et al., 2000). Since the temperature is a basic element for the climate formation, its variations could drastically change the climate structure of anyplace. This is why the analysis of the temperature trend in different time and spatial scale has allocated a great part of climatology researches (Masoodian, 2004).

Predictions indicate that the increase of greenhouse gases would increase the world temperature between 4.5 to 1.5 centigrade and the current sea level between 20 to 140 centimeters by 2030 (Azizi, 2004). The largeness of the predicted temperature increase could potentially lead to a change in water cycle, and cause more precipitations; rapid evaporation and change in current water and intensifies the hydrological abnormalities such as drought and flood (Azizi et al., 2008). Considering the ability of the greenhouse gases to trap heat and cause changes in the world temperature, the studies on contemporary climate variations focus mainly on temperature variations (Ghil \& vautard, 1991; North et al., 1995; Esterling et al., 1997; Chung \& Yoon, 2000; Jones Research article CCIndian Society for Education and Environment (iSee)
\& Moberg 2003; Luterbache et al., 2004; Doglouss et al., 2007). In Iran, extensive studies have been conducted on temperature variations in different regions. Kaviani and Asakare (2001) have analyzed and presented a model for temperature trend in the last century in Jask.

Their results indicate that the temperature of Jask has had a rising trend in the last century. Rahimzadeh and Asgari (2004) have studied the difference between the minimum and maximum rate of temperature increase and the decrease of temperature range during day and night in the country. Their results have shown that the minimum temperature has the rising trend in most regions of the country. Jahanbakhsh and Torabi (2004) have analyzed and predicted the temperature and precipitation variations in Iran and have shown that the rate of minimum temperature in north and mountainous regions of Iran had significant changes. Ghavidel Rahimi (2005) has analyzed the sensibility of temperature and precipitation in Tabriz city to the increase of carbon dioxide in atmosphere using joint atmosphere-ocean global warming models and has shown that Tabriz temperature would increase in the condition of doubling atmosphere carbon dioxide in all monthly, annual and seasonal sections. Since Fars province is considered as one the largest provinces of Iran and it has the high potential in terms of agriculture especially cereal and tourism attraction, the need to study variations in temperature components with regard to the increase of the atmosphere carbon dioxide in this province is felt. Because a good understanding of temperature variations as a very important climate component in the realm of "Climate change" http://www.indjst.org
A.A.Sabzevari \& G.R.Miri Indian J.Sci.Technol. 
global warming could provide an appropriate perspective for the managers in order to plan in the areas of agriculture, energy and tourism to get maximum efficiency from natural conditions, decrease losses with regard to the risk management and to have good understanding of the future climate variations.

\section{Methods and materials}

In the present study, it has been attempted to survey the relationship between the effects of density of carbon dioxide in atmosphere and temperature variations in Fars province. For this purpose, the data from three temperature parameters (mean, minimum and maximum) of six climatological stations of Fars province in a 15-year statistical period (1990-2005) were extracted from Iran Meteorology Organization. Then, the going trend in the above-mentioned temperature parameters was studied in monthly scale (Fig.1). Following that the correlation between the rate of atmosphere carbon dioxide as registered in Manaloa station with the temperature parameters of the mentioned six stations have been evaluated by using two-variable correlation and linear regression in both monthly and annual scale. It is necessary to be mentioned that carbon dioxide data have been used and extracted from NASA website and then used.

Fig. 1. Dispersion of research stations in Fars province, Iran

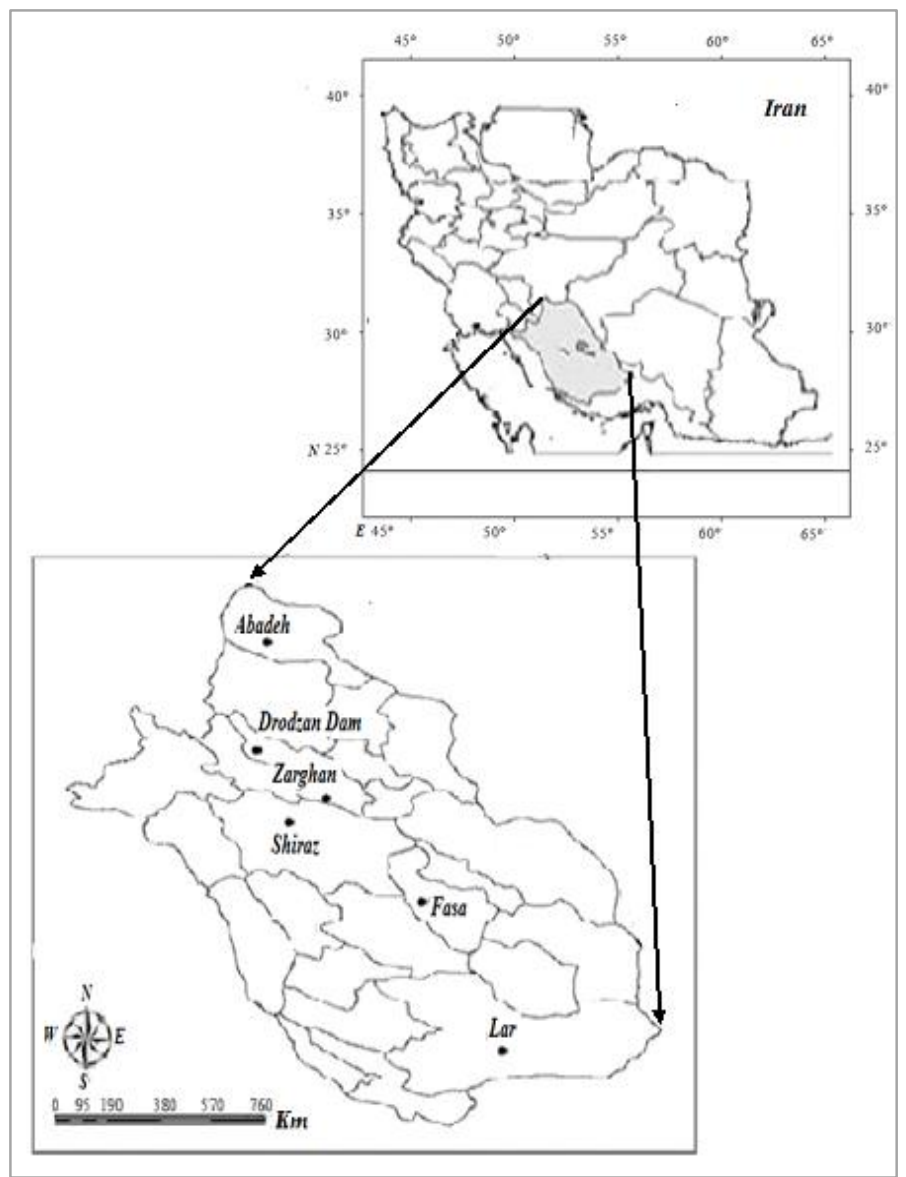

\section{Research findings}

Based on the analysis, temperature variations have the rising trend in all stations of Fars province. In this regard, the minimum temperature has shown more significant and more rising trend in all stations except in Shiraz and Doroodzan dam. The rate of temperature rise for the temperature mean in Fars province has the lowest rate of variation. With regard to the minimum temperature parameter, the maximum rate of increase is related to Abadeh station with the significant coefficient of 0.78 . In contrast, the lowest rising trend in minimum temperature could be seen in Shiraz and Doroodzan dam stations respectively with the significant coefficient of 0.22 and 0.39. Furthermore, the most rate of increase regarding the maximum temperature is related to Zarghan station with the significant coefficient of 0.70 and the least is related to Fasa station $(r=0.41)$. Moreover, the most rate of increase of the mean temperature has been occurred in Zarghan station $(r=0.68)$ and the least is occurred in Shiraz station $(r=0.36)$.

Figs. 2-7 show temperature parameter variations in Fars province. With regard to these figures we could understand the rate of temperature rise in the studied statistical period.

Also, data related to the density of atmosphere carbon dioxide in Manaloa station during the studied statistical period indicates the rising trend. Indeed, in the recent years with human manipulation, the amount of greenhouse gases and specially carbon dioxide has had a rising trend. The density of atmosphere carbon dioxide was approximately 354 (PPM) in 1990; this rate has been increased to an approximate amount of 379.4 (PPM) in 2005. Accumulation of carbon dioxide in atmosphere could make variations in temperature of regions. The most important effect of atmosphere carbon dioxide is the prevention from the emission of long-wave radiation from the earth; this causes the gradual increase of temperature. Fig. 8 shows the atmosphere carbon dioxide variations in Manaloa station in statistical period of 19902005.

The amount of atmosphere carbon dioxide varied with regard to the different conditions during the year and in different months; so that the most concentration of carbon dioxide in the atmosphere is seen in spring and the least concentration is related to early fall.

The analysis of the correlation between the increases of atmosphere carbon dioxide and temperature values of different stations of Fars province indicate that there is a significant correlation between the increase of carbon dioxide and temperature values (Fig.9). The correlation between carbon dioxide and temperature variations varied in different months. Based on Tables 1 to 6 , the correlation between temperature parameters and the rate of atmosphere carbon dioxide is highly significant in all studied stations in February, March and October. Therefore, the highest correlation is related to these months.
Research article

CCIndian Society for Education and Environment (iSee)
"Climate change"

http://www.indjst.org
A.A.Sabzevari \& G.R.Miri Indian J.Sci.Technol. 
Table 1. The Correlation between the amounts of carbon dioxide emitted into the atmosphere and the temperature of shiraz station

\begin{tabular}{|c|c|c|c|c|c|c|c|c|c|c|c|c|}
\hline $\begin{array}{c}\text { month } \\
\text { Parameter }\end{array}$ & jan & feb & mar & apr & may & jun & jul & aug & sep & oct & nov & dec \\
\hline Min Tem & 0.26 & ${ }^{*} 0.59$ & ${ }^{*} 0.47$ & 0.22 & 0.15 & 0.2 & 0.15 & 0.1 & 0.1 & ${ }^{*} 0.6$ & 0.15 & 0.13 \\
\hline Daily Tem & 0.3 & 0.52 & 0.64 & 0.31 & 0.2 & 0.3 & 0.25 & 0.15 & 0.2 & 0.55 & 0.27 & 0.14 \\
\hline Max Tem & 0.38 & ${ }^{*} 0.5$ & ${ }^{*} 0.63$ & 0.37 & 0.2 & 0.26 & 0.18 & 0.1 & 0.24 & ${ }^{*} 0.54$ & 0.22 & 0.1 \\
\hline
\end{tabular}

Table 2. The correlation between the amounts of carbon dioxide emitted into the atmosphere and the temperature of Abadeh station

\begin{tabular}{|c|c|c|c|c|c|c|c|c|c|c|c|c|}
\hline $\begin{array}{c}\text { Month } \\
\text { Parameter }\end{array}$ & jan & feb & mar & apr & may & jun & jul & aug & sep & oct & nov & dec \\
\hline Min Tem & 0.38 & $0.51^{*}$ & $0.71^{*}$ & 0.66 & 0.12 & 0.57 & 0.37 & 0.41 & 0.68 & $0.74^{*}$ & 0.15 & 0.15 \\
\hline Daily Tem & 0.4 & $0.47^{*}$ & $0.59^{*}$ & 0.45 & 0.15 & 0.46 & 0.22 & 26 & 0.54 & $0.59^{*}$ & 0.1 & 0.12 \\
\hline Max Tem & 0.35 & $0.49^{*}$ & $0.67^{*}$ & 0.33 & 0.17 & 0.26 & 0.1 & 0.12 & 0.37 & $0.71^{*}$ & 0.18 & 0.16 \\
\hline
\end{tabular}

Table 3. The correlation between the amounts of carbon dioxide emitted into the atmosphere and the temperature of Lar station

\begin{tabular}{|c|c|c|c|c|c|c|c|c|c|c|c|c|}
\hline $\begin{array}{c}\text { Month } \\
\text { parameter }\end{array}$ & jan & feb & mar & apr & may & jun & jul & aug & sep & oct & nov & dec \\
\hline Min Tem & 0.2 & $0.5^{*}$ & $0.52^{*}$ & 0.47 & 0.28 & 0.47 & 0.47 & 20 & 0.36 & $0.62^{*}$ & 0.34 & 0.12 \\
\hline Daily Tem & 0.25 & $0.44^{*}$ & $0.63^{*}$ & 0.46 & 0.25 & 0.38 & 0.46 & 0.21 & 0.36 & $0.49^{*}$ & 0.15 & 0.23 \\
\hline Max Tem & 0.23 & $0.47^{*}$ & $0.55^{*}$ & 0.42 & 0.2 & 0.1 & 0.48 & 0.16 & 0.29 & $0.61^{*}$ & 0.11 & 0.15 \\
\hline
\end{tabular}

Table 4. The correlation between the amounts of carbon dioxide emitted into the atmosphere and the temperature of Doroodzan dam

\begin{tabular}{|c|c|c|c|c|c|c|c|c|c|c|c|c|}
\hline $\begin{array}{c}\text { Month } \\
\text { parameter }\end{array}$ & jan & feb & mar & apr & may & jun & jul & aug & sep & oct & nov & dec \\
\hline Min Tem & 0.15 & $0.58^{*}$ & $0.57^{*}$ & 0.3 & 0.16 & 0.61 & 0.12 & 0.22 & 0.1 & $0.73^{*}$ & 0.35 & 0.14 \\
\hline Daily Tem & 0.18 & $0.53^{*}$ & $0.53^{*}$ & 0.34 & 0.15 & 0.58 & 0.1 & 0.2 & 0.16 & $0.6^{*}$ & 0.23 & 0.1 \\
\hline Max Tem & 0.22 & $0.54^{*}$ & $0.45^{*}$ & 0.37 & 0.24 & 0.42 & 0.2 & 0.18 & 0.3 & $0.71^{*}$ & 0.16 & 0.1 \\
\hline
\end{tabular}

Table 5. The correlation between the amounts of carbon dioxide emitted into the atmosphere and the temperature of Zarghan station

\begin{tabular}{|c|c|c|c|c|c|c|c|c|c|c|c|c|}
\hline $\begin{array}{c}\text { Month } \\
\text { parameter }\end{array}$ & jan & feb & mar & apr & may & jun & jul & aug & sep & oct & nov & dec \\
\hline Min Tem & 0.28 & $0.57^{*}$ & $0.66^{*}$ & 0.47 & 0.42 & 0.75 & 0.47 & 0.25 & 0.63 & $0.71^{*}$ & 0.26 & 0.24 \\
\hline Daily Tem & 0.33 & $0.56^{*}$ & $0.45^{*}$ & 0.46 & 0.4 & 0.76 & 0.25 & 0.26 & 0.54 & $0.75^{*}$ & 0.1 & 0.21 \\
\hline Max Tem & 0.3 & $0.55^{*}$ & $0.65^{*}$ & 0.42 & 0.43 & 0.53 & 0.1 & 0.2 & 0.41 & $0.7^{*}$ & 0.15 & 0.27 \\
\hline
\end{tabular}

Table 6. The correlation between the amounts of carbon dioxide emitted into the atmosphere and the temperature of fasa station

\begin{tabular}{|c|c|c|c|c|c|c|c|c|c|c|c|c|}
\hline $\begin{array}{c}\text { Month } \\
\text { parameter }\end{array}$ & jan & feb & mar & apr & may & jun & jul & aug & sep & oct & nov & dec \\
\hline Min Tem & 0.38 & $0.55^{*}$ & $0.67^{*}$ & 0.54 & 0.22 & 0.6 & 0.56 & 0.45 & 0.33 & $0.77^{*}$ & 0.41 & 0.37 \\
\hline Daily Tem & 0.38 & $0.52^{*}$ & $0.65^{*}$ & 0.45 & 0.23 & 0.54 & 0.32 & 0.33 & 0.22 & $0.7^{*}$ & 0.2 & 0.25 \\
\hline Max Tem & 0.24 & $0.45^{*}$ & $0.57^{*}$ & 0.38 & 0.22 & 0.27 & 0.11 & 0.18 & 0.15 & $0.69^{*}$ & 0.26 & 0.1 \\
\hline
\end{tabular}

* Significance of the correlation between carbon dioxide variations and temperature Indian J.Sci.Technol. 
Fig. 2. Temperature variation trend in Shiraz station (1990-2005)

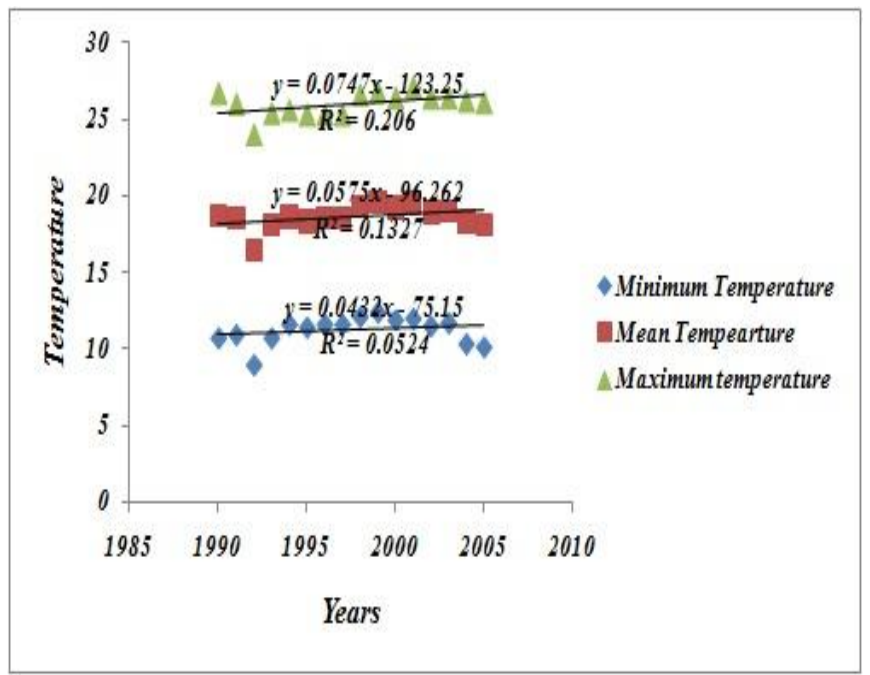

Fig. 4. Temperature variation trend in lar station (1990-2005)

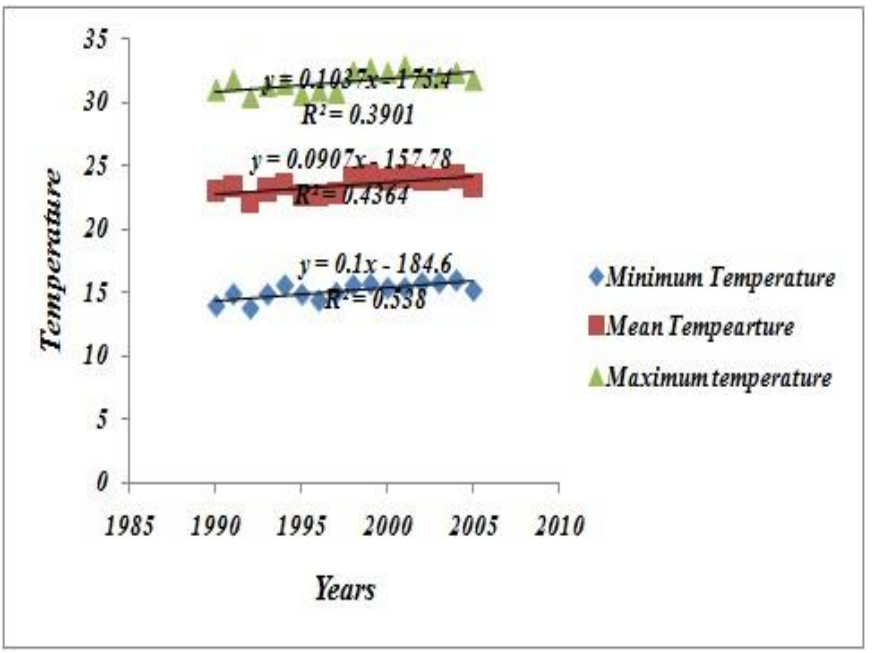

Fig. 6. Temperature variation trend in Zarghan station (1990-2005)

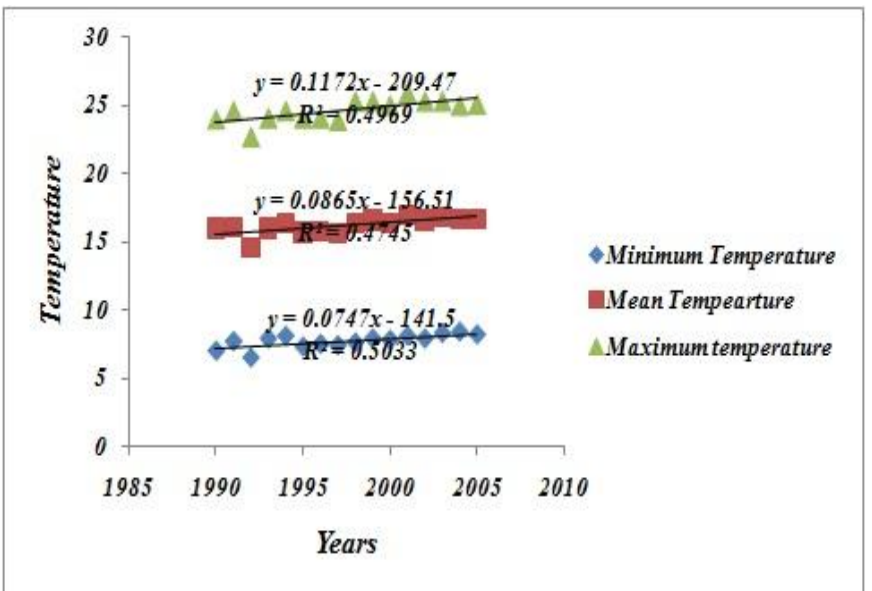

Vol. 5 No. $9 \quad$ (Sep. 2012)

ISSN: 0974- 6846

Fig. 3. Temperature variation trend in Abadeh station (1990-2005)

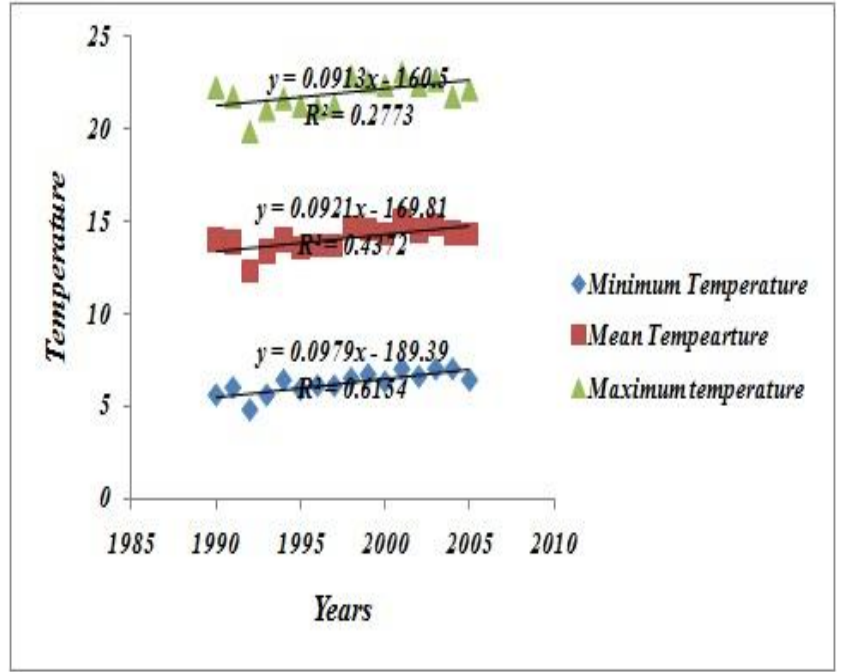

Fig. 5. Temperature variation trend in Doroodzan dam (1990-2005)

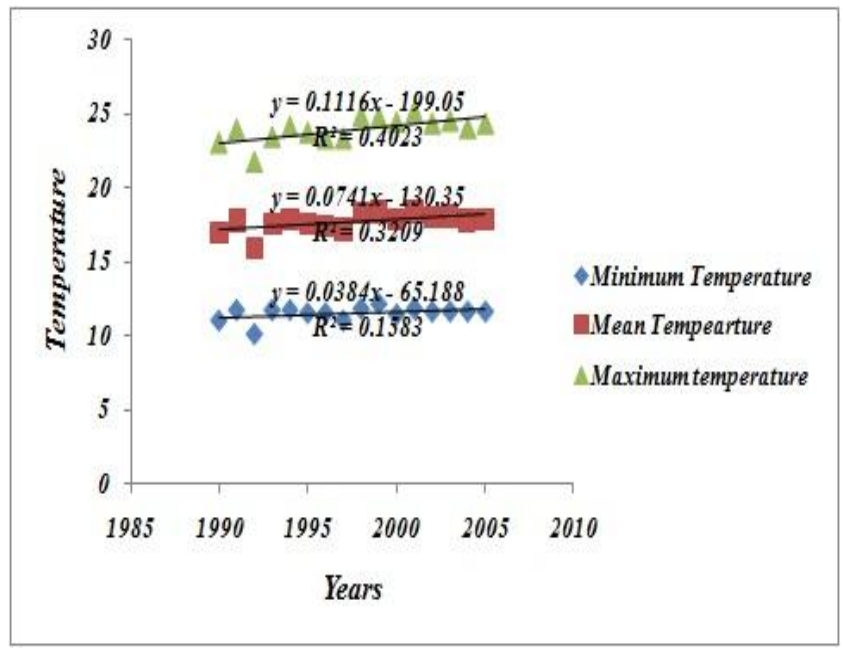

Fig. 7. Temperature variation trend in Fasa (1990-2005)

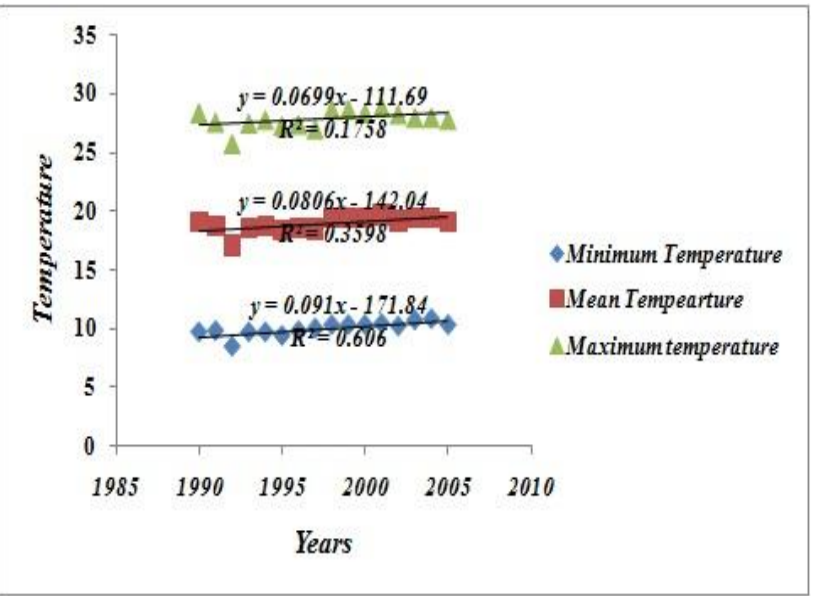

Research article

CCIndian Society for Education and Environment (iSee)

"Climate change" http://www.indjst.org
A.A.Sabzevari \& G.R.Miri Indian J.Sci.Technol. 
Fig. 8. Atmosphere carbon dioxide variations during the years 1990 to 2005

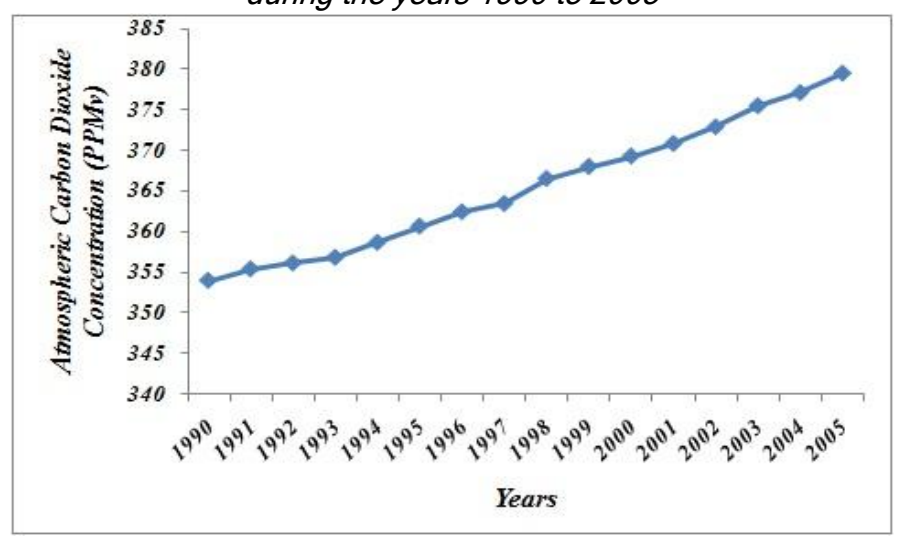

Fig.9. Monthly variation trend of atmosphere carbon dioxide concentration

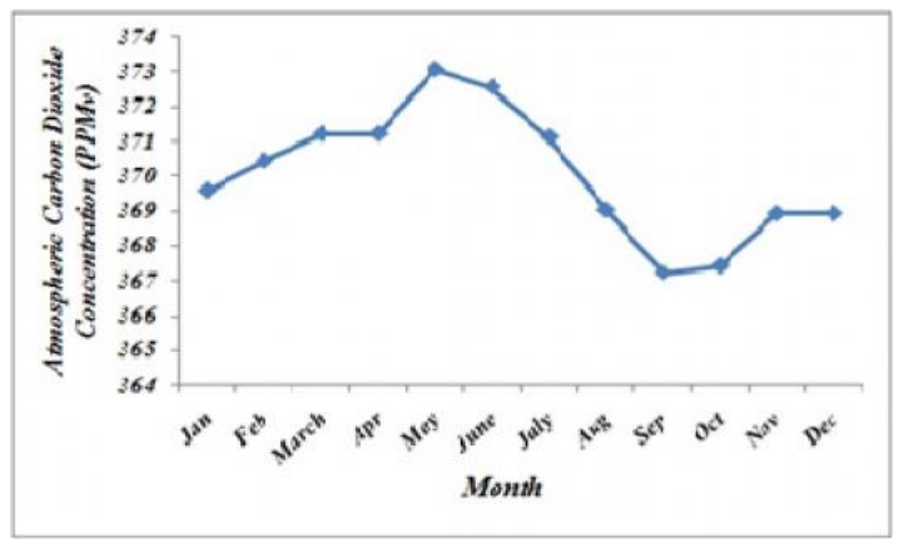

Indeed, the most correlation between the atmosphere carbon dioxide and temperature condition in Fars province is simultaneous with equinox event. During the equinox, the sun shines vertically on equator. The length of day and night is equal throughout the earth; it is 12 hours day and 12 hours night (Alijani, 2001). In this condition, total hours of incoming energy (short-wave) and outgoing energy (long-wave) would be equal.

Therefore, during the night, the atmosphere carbon dioxide plays an important role in the prevention from the emission of long waveform the earth and causes the increase in night temperature (the minimum temperature).

The most correlation between the atmosphere carbon dioxide and the minimum temperature mean is observed in February, March and October. Furthermore, among the studied stations Fasa station has the most significant coefficient in October for the minimum temperature of 0.77 .

Also in annual scale, significant correlations observed between the increase of carbon dioxide and temperature variations in Fars Province; and the minimum temperature has the most correlation with the atmospheric carbon dioxide. In this regard, the minimum temperature of Fasa station with the correlation coefficient of 0.81 has shown the most correlation and in contrast, the minimum temperature of Doroodzan dam with the amount of 0.42 has shown the least correlation with the density of atmosphere carbon dioxide. Indeed, the reason for more correlation between atmosphere carbon dioxide and the minimum temperature variations is the greenhouse conditions provided by carbon dioxide which crossed the solar short waves during the day and prevent from the emission of long wave radiations from the earth during the night (Fig.10).

\section{Conclusion}

Considering the effect of temperature variations on other climate parameters and consequently its influence on climate change, in this research, it has been attempted to study the effects of the increase of carbon dioxide emitted into the atmosphere, as the most important greenhouse gas on temperature parameter variations in Fars province. The obtained results indicate that the three temperature parameters (average, minimum and maximum) in the studied statistical period have the rising trend in all studied stations, among which the most increasing coefficient is related to minimum temperature. On the other hand, evaluating the correlation between the amount of atmosphere carbon dioxide which is registered in Manaloa station and the temperature parameters has shown that the most significant coefficient between these variations is related to February, March and October; the amount of carbon dioxide emission in these months taking a rising trend. In other words, the obtained results have shown that there has been a significant correlation between the increases of carbon dioxide in the atmosphere and the increase of temperature, and the most increasing coefficient is related to minimum temperature. This has shown that most of what which is regarded as warming is the rising temperature during the night. In other words, by the increase of temperature resulting from the increase of carbon dioxide emitted into the atmosphere, the amount of evaporation is increased and by the increase of cloud coverage, the amount of incoming shortwave radiation is decreased during the sunny hours; therefore the increase of temperature occurred less during the day. In contrast, by the increase of cloud coverage during the night, less energy is emitted into the atmosphere from the earth; therefore the night temperature is increased. Hence, with regard to the significance of the minimum temperature in temperature variations and the warming trend, the study of the variations of this parameter in different stations have shown that the most increasing coefficient of the minimum temperature in the studied statistical period was related to Abadeh station $(r=0.78)$. However, in contrast, the most correlation coefficient between the amount of atmosphere carbon dioxide and the minimum temperature, is related to Fasa station in both monthly and annual scale with the rate of $r=0.81$ and $r=0.77$ respectively.
Research article

Clndian Society for Education and Environment (iSee)
A.A.Sabzevari \& G.R.Miri Indian J.Sci.Technol. 
Fig. 10: $r^{2}$ Between the amounts of carbon dioxide and annual mean of the minimum temperature in Shiraz station (a), Abadeh(b), Lar(c), Doroodzan dam(d), Zarghan(e) and Fasa(f).
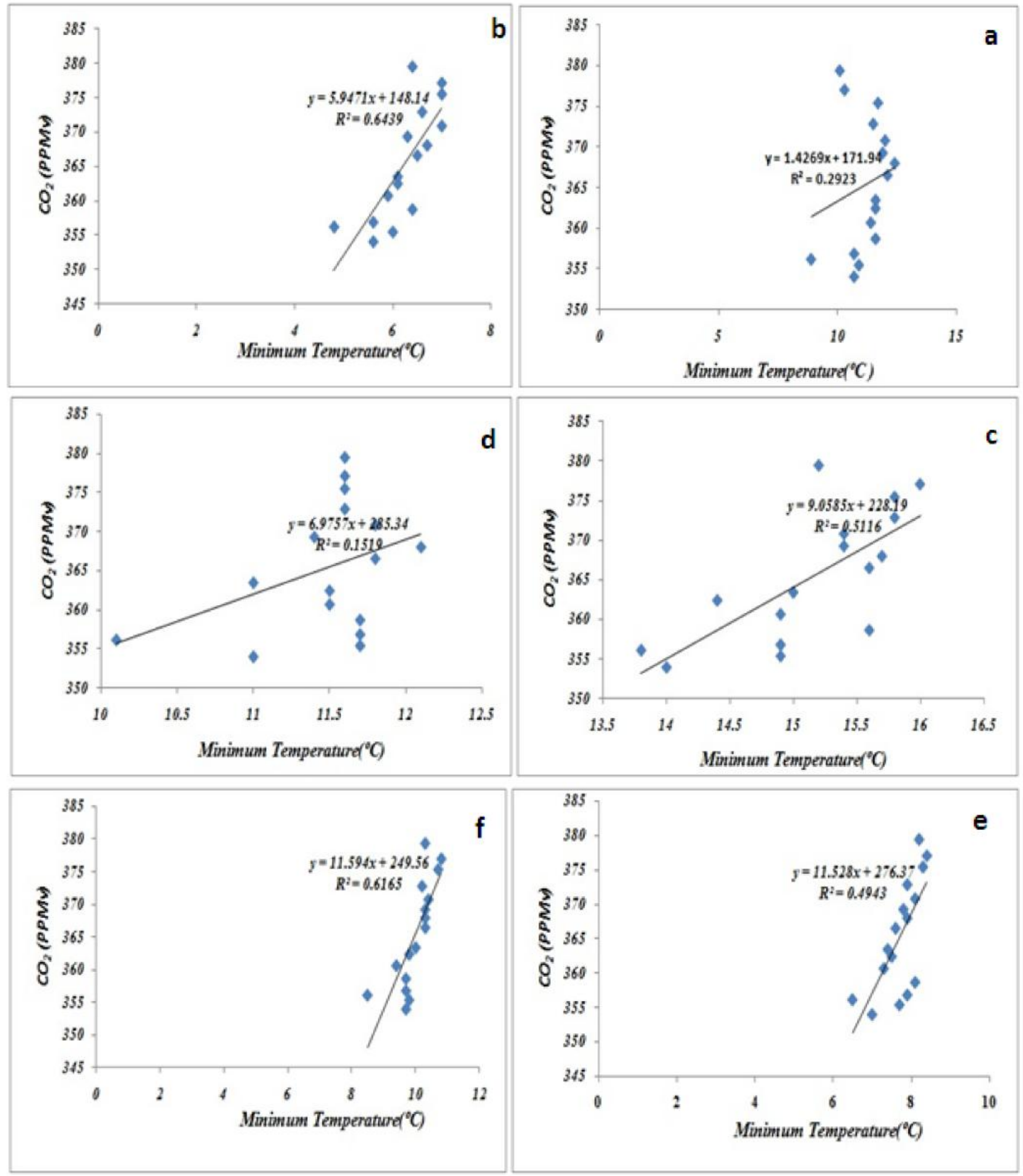


\section{References}

1. Azizi Gh (2004) Climate change. Ghoomes Press, Tehran. pp: 210.

2. Azizi Gh and Rowshani M (2008) Analyzing climate changes of south coast of Caspian sea. Geographical Res. Seasonal. 10(12), 13-24.

3. Alijani b (2001) Fundamentals of climatology. SAMT Press. Tehran. pp: 359.

4. Chung YS and Yoon MB (2000) Interpretation of recent temperature and precipitation trends observed in Korea. Theoretical \& Appl. Climatol. 14(67), 171180.

5. Doglouss David H, Christy John R and Singer S Fred (2007). A comparison of tropical temperature trends with model predictions. Int. J. Climatol. 21(28), 16931701.

6. Easterling D, Horton b, Philip D, Jones Thomas C Peterson, Thomas R Karl, David E Parker, James Salinger M, Vyacheslav Razuvayev, Neil Plummer, Paul Jamason and Christopher K Folland (1997) Maximum and minimum temperature trends for the globe. Sci. 58(277), 364-367.

7. Ghil M and Vautard R (1991) Interdecadal oscillations and the warming trend in global temperature time series. Sci. 199(45), 1065-1068.

8. Jones PD and Moberg A (2003) Hemispheric and large-scale surface air temperature variations: An Extensive Revision and an Update to 2001. J. Climate. 12(21), 206-223.

9. JahanbakhshAsl S and Torabi S (2004) Analyzing and forecasting precipitation and temperature variations in Iran. Geographic Res. Seasonal. 74(11), 104-125.

10. GhavidelRahimi Y (2005) The sensibility of temperature and precipitation in Tabriz city to the increase of carbon dioxide in atmosphere using joint atmosphere-ocean global warming models. Humanities Instructors Seasonal. 21(10), 102-123.

11. Kaviani M and Asakareh H (2001) Analyzing and modeling temperature during the last century (case study: Jask station). Humanities and literature J., Esfahan Univ. 27(11), 19-38.

12. Luterbacher J, Dietrich D, Xoplaki E, Grosjean M and Wanner H (2004) European seasonal and annual temperature variability, trends, and extremes since 1500. Sci. 303(44), 1499-1503.

13. Mohammadi $H$ (2004) Atmosphere processes and systems. Tehran Univ. Press, Tehran. pp: 156.

14. Masoudian SA (2004) Analyzing Iran's temperature trend in the half of the last century. Development \& Geography J. 23(4), 89-106.

15. North GR and Kim KY (1995) Detection of forced climate signals. Part II: Simulation results. J. Climate. 6(12), 409-417.
Vol. 5 No. $9 \quad$ (Sep. 2012)

ISSN: 0974- 6846

16. Pourkhabaz AR and Hamidreza (2004) The most important environmental disturbances of the present country. Astan Ghods Razavi Press, Mashhad.

17. Rahimzadeh $F$ and Asgari A (2004) An approach to the difference between rising rate of minimum and maximum temperature and the decrease of temperature range during day and night in the country. Geographic Res. Seasonal. 73(45):155-175.

18. Shirgholami H and Ghahreman B (2005) Analyzing the trend of annual mean temperature in Iran. Natural Res. \& Agri. Technol. Sci. J. 12(9), 9-25.

19. Vaseghi E and Esmaeili Abdolkarim (2009) Analyzing determining factors in carbon dioxide emission in Iran (application of Kuznets environmental theory). Environ. Studies J. 52(11), 99-110. 